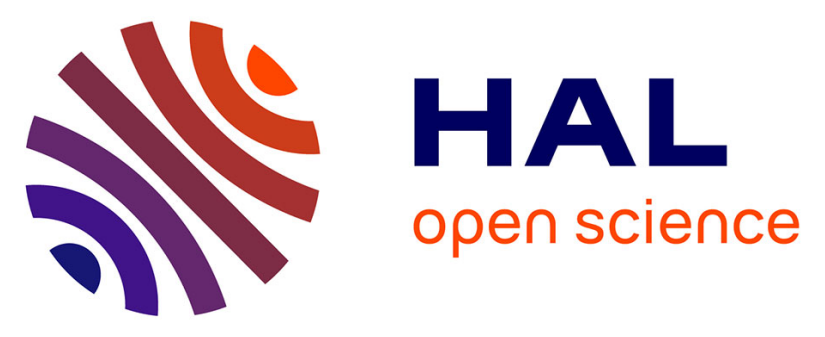

\title{
Primary sclerosing cholangitis response to the combination of fibrates with ursodeoxycholic acid: French-Spanish experience
}

Sara Lemoinne, Albert Pares, Anna Reig, Karima Ben Belkacem, Astrid Donald Kemgang Fankem, Farid Gaouar, Raoul Poupon, Chantal Housset, Christophe Corpechot, Olivier Chazouillères

\section{To cite this version:}

Sara Lemoinne, Albert Pares, Anna Reig, Karima Ben Belkacem, Astrid Donald Kemgang Fankem, et al.. Primary sclerosing cholangitis response to the combination of fibrates with ursodeoxycholic acid: French-Spanish experience. Clinics and Research in Hepatology and Gastroenterology, 2018, 42 (6), pp.521-528. 10.1016/j.clinre.2018.06.009 . hal-02052427

\section{HAL Id: hal-02052427 https://hal.sorbonne-universite.fr/hal-02052427}

Submitted on 28 Feb 2019

HAL is a multi-disciplinary open access archive for the deposit and dissemination of scientific research documents, whether they are published or not. The documents may come from teaching and research institutions in France or abroad, or from public or private research centers.
L'archive ouverte pluridisciplinaire HAL, est destinée au dépôt et à la diffusion de documents scientifiques de niveau recherche, publiés ou non, émanant des établissements d'enseignement et de recherche français ou étrangers, des laboratoires publics ou privés. 


\section{Primary sclerosing cholangitis response to the combination of fibrates with ursodeoxycholic acid: French-Spanish experience}

Sara Lemoinne ${ }^{1,2}$, Albert Pares ${ }^{3}$, Anna Reig $^{3}$, Karima Ben Belkacem ${ }^{1,2}$, Astrid Donald

Kemgang Fankem ${ }^{1,2}$, Farid Gaouar ${ }^{1}$, Raoul Poupon ${ }^{1}$, Chantal Housset ${ }^{1,2}$ Christophe $^{2}$

Corpechot $^{1,2}$, Olivier Chazouillères ${ }^{1,2}$

${ }^{1}$ Assistance-Publique Hôpitaux de Paris, Hepatology department, Reference center for Inflammatory biliary diseases and autoimmune hepatitis, Saint-Antoine Hospital, 184 rue du Faubourg Saint-Antoine, 75012 Paris, France

${ }^{2}$ Sorbonne Université, INSERM, Centre de Recherche Saint-Antoine (CRSA), Faculté de médecine, Site Saint-Antoine, 27 rue de Chaligny, 75012, Paris, France

${ }^{3}$ Liver Unit, Hospital Clínic, IDIBAPS, CIBERehd, Univesity of Barcelona, Carrer de Villarroel, 170, 08036 Barcelona, Spain

\section{Email addresses of authors (Given name FAMILY NAME):}

Sara LEMOINNE: sara_lemoinne@,yahoo.fr

Albert PARES: apares@,clinic.cat

Anna REIG: anna.rg86@gmail.com

Karima BEN BELKACEM: karima.benbelkacem@aphp.fr

Astrid Donald KEMGANG FANKEM: kastriddonald@yahoo.fr

Farid GAOUAR: farid.gaouar@aphp.fr

Raoul POUPON: Raoul.poupon@orange.fr

Chantal HOUSSET: $\underline{\text { Chantal.housset@inserm.fr }}$

Christophe CORPECHOT: Christophe.corpechot@aphp.fr

Olivier CHAZOUILLERES: Olivier.chazouilleres@aphp.fr 


\section{Author contributions:}

SL and OC decided the study design. SL, AP, KBB, ADKF and FG collected the data. SL analyzed and interpreted the data. CC participated to statistical analysis. SL drafted the manuscript. AP, AR, CC, CH, RP and OC performed critical revision of the manuscript.

\section{Corresponding author:}

Olivier Chazouillères

Postal address: Service d'Hépatologie, Hôpital Saint-Antoine, 184 rue du Faubourg SaintAntoine, 75012 PARIS, France

Telephone : +33149282378 Fax : +33149282107

Email address: olivier.chazouilleres@aphp.fr

Conflict of interest declaration: The authors have no conflict of interest. 


\begin{abstract}
Background \& Aims: In patients with primary sclerosing cholangitis (PSC), ursodeoxycholic acid (UDCA) treatment improves serum liver tests and surrogate markers of prognosis but has no proven effect on survival. Additional therapies are obviously needed. Fibrates, PPAR agonists with anti-cholestatic properties, have a beneficial effect in primary biliary cholangitis. The aim of this study was to evaluate the safety and efficacy of fibrates in PSC patients.
\end{abstract}

Methods: Retrospectively, we investigated PSC patients treated with fibrates (fenofibrate $200 \mathrm{mg} /$ day or bezafibrate $400 \mathrm{mg} /$ day) for at least 6 months in addition to UDCA, after an incomplete biochemical response (Alkaline Phosphatase (ALP) $>1.5 \mathrm{x}$ upper limit of normal) to UDCA. Changes in biochemical parameters and clinical features were assessed.

Results: Twenty patients were included (fourteen from Paris and six from Barcelona): median age 43.8 years, median liver stiffness $11 \mathrm{kPa}(\geq \mathrm{F} 3)$. Upon treatment with fibrates (median duration of 1.56 years), liver tests significantly improved, including a reduction of ALP levels by $41 \%$ and pruritus significantly decreased. No serious adverse event attributable to fibrates occurred. Discontinuation of fibrates was followed by a clear rebound of ALP. Despite biochemical improvement, liver stiffness significantly increased.

Conclusions: Combining UDCA with fibrates results in a significant biochemical improvement and pruritus decrease in PSC patients with incomplete response to UDCA. These results provide a rationale for larger and prospectively designed studies to establish the efficacy and safety of fibrates in PSC.

\title{
Keywords
}

Chronic liver diseases; cholestasis; liver fibrosis; cirrhosis 


\section{Abbreviations}

ALP: Alkaline Phosphatase

ALT: Alanine Aminotransferase

AST: Aspartate Aminotransferase

CPK: Creatine Phospho kinase

GGT: Gamma-Glutamyltranspeptidase

IBD: Inflammatory Bowel Disease

LT: Liver Transplantation

PBC: Primary Biliary Cholangitis

PPAR: Peroxisome Proliferator-Activated Receptor

PSC: Primary Sclerosing Cholangitis

SEM: Standard Error of the Mean

UDCA: Ursodeoxycholic Acid

ULN: Upper Limit of Normal

\section{Acknowledgements}

Fonds CSP 


\section{Introduction}

Primary sclerosing cholangitis (PSC) is a rare, chronic cholestatic liver disease of unknown cause commonly associated with inflammatory bowel disease (IBD) and characterized by progressive obliterative fibrosis of the biliary tract $[1,2]$. Although the natural course may be variable from one patient to another, PSC is often progressive, leading to biliary cirrhosis, its complications and lethal outcome. In addition, PSC is a condition harbouring high neoplastic risk with increased susceptibility for the development of cholangiocarcinoma and colon cancer when associated with IBD. At this time, there is no medical treatment of proven efficacy for PSC. Ursodeoxycholic acid (UDCA), the current backbone of treatment in chronic cholestatic diseases, is recommended in primary biliary cholangitis (PBC) but, in PSC, treatment guidelines [3-5] are conflicting. This is because, despite usual improvement of liver tests, proven benefit on the survival of PSC patients is lacking, while decreased eventfree survival has even been reported with high doses [6]. As a result, the use of UDCA at moderate doses is common but still depends on local policy. Therefore, liver transplantation (LT) remains the only validated treatment and there is a clear need for medical treatment.

In the last two decades, numerous open studies have shown that fibrates, commonly associated with UDCA, improved liver biochemistries in PBC [7-10]. These promising results were recently confirmed by a large randomized controlled trial of bezafibrate in PBC patients with inadequate response to UDCA [11] and in a long-term outcome study of bezafibrate [12]. Fibrates are agonists of the peroxisome proliferator-activated receptors (PPAR), especially the $\alpha$ isoform, used in the treatment of hypertriglyceridemia. Fibrates were incidentally noted to cause a decrease in serum liver biochemistries. Mechanisms of their beneficial effects in chronic cholestasis include anti-inflammatory actions, decreased bile acid synthesis and enhanced phospholipids biliary secretion [13]. Overall, there was strong 
rationale to test fibrates as a therapeutic option in PSC patients, especially those with poor response to UDCA. Experience with fibrates in PSC is very scarce and is limited to small case series with short follow-up but preliminary results mostly from Japan appear encouraging [1417]. Herein, we report on the combined experience of two European reference centers for chronic cholestatic liver diseases, evaluating the efficacy and safety of fibrates in PSC patients with incomplete biochemical response to UDCA.

\section{Patients and methods}

\section{Patients}

We retrospectively investigated patients from two European expert centers for chronic cholestatic liver diseases: Paris and Barcelona. Inclusion criteria were (i) an established diagnosis of large duct PSC according to published criteria: chronic cholestasis, multifocal strictures on magnetic resonance cholangiography and no cause of secondary cholangitis [3] (ii) treatment with UDCA $(15-20 \mathrm{mg} / \mathrm{kg} / \mathrm{d})$ for at least 1 year, (iii) persistent elevation of serum alkaline phosphatase (ALP) $>1.5$ upper limit of normal (ULN) under UDCA and (iv) additive treatment with fibrates for at least six months. Exclusion criteria were: associated autoimmune hepatitis (overlap syndrome), small duct PSC, secondary sclerosing cholangitis (especially IgG4 disease), co-existing liver disease or severe extra-hepatic disease, cholangiocarcinoma, decompensated cirrhosis, previous liver transplantation, acute or chronic renal failure. 


\section{Methods}

The treatment with fibrates was decided by expert hepatologists. Before starting treatment, patients were informed of the off-label use, expected benefits and adverse effects of fibrates. All patients provided written informed consent. A single daily dosage of fenofibrate (200 $\mathrm{mg}$ /day) or bezafibrate (400 mg/day) was added to UDCA (15-20 mg/kg/day) treatment. The choice of fibrates was center-dependent: Paris patients were given fenofibrate while Barcelona patients were given bezafibrate. Demographic characteristics and history of PSC (date of diagnosis, association with IBD) were recorded. Follow-up was based on physical examination every six months, liver tests (Aspartate aminotransferase (AST), alanine aminotransferase (ALT), ALP, gamma-glutamyltranspeptidase (GGT), total bilirubin, Prothrombin Time, albumin) and general blood tests (blood count, creatinine, cholesterol, triglycerides, creatine phosphokinase (CPK), IgG, IgM) every 3 months during the first year and every six months, thereafter. Liver stiffness was measured by an expert physician or nurse, using transient elastography (FibroScan, Echosens, Paris, France), every year. Pruritus was systematically assessed every 6 months by the expert hepatologist during follow-up. The intensity of pruritus was rated by the physician on a semi-quantitative scale: grade 0 , none: grade 1, mild; grade 2, moderate; grade 3, severe. Potential adverse events and disease clinical features were evaluated at each visit. Fibrates were discontinued if intrahepatic biliary stones occurred or in case of poor tolerance including the worsening of blood liver tests under treatment.

\section{Statistical analysis}

Descriptive statistics are expressed as medians [range]. Continuous variables were compared using Mann-Whitney test or Wilcoxon matched pairs test when appropriate. 
Qualitative variables were compared using chi-squared test. The changes in biochemical parameters and liver stiffness over the total duration of treatment, were analyzed using a linear mixed model considering random effects for subjects. Kaplan-Meier's analysis was used to estimate transplant-free survival. Log-rank test was performed to compare actual survival with that predicted by the revised Mayo Risk Score [18]. Significance was defined by $\mathrm{p}<0.05$. Statistical analysis was performed using PRISM 2013 and XLSTAT 19.5.

\section{Results}

\section{Study population}

Twenty patients (fourteen in Paris and six in Barcelona) were included between January 2009 and December 2012. The time of inclusion was defined by the date of initiation of fibrates. The main characteristics of patients at inclusion are reported in Table 1.

Seventy five percent of the patients were males and $70 \%$ had IBD (ulcerative colitis: $86 \%$, Crohn's disease: 14\%). Fifteen patients (75\%) had both intra and extrahepatic disease, whereas the intrahepatic biliary tract was exclusively involved in five patients $(25 \%)$. Thirteen patients $(65 \%)$ had liver biopsy, performed at the time of PSC diagnosis. The time between liver biopsy and inclusion was 2.8 years [0.07-15.6]. Among patients with liver biopsy, seven patients (54\%) displayed severe fibrosis (F3 according to Metavir score). At inclusion, seven patients (35\%) had cirrhosis as attested by liver stiffness $>14.4 \mathrm{kPa}$ measured by transient elastography [19]. Among all twenty patients, eight patients (40\%) had pruritus at inclusion; only one patient (5\%) had bilirubinemia $>2.9 \mathrm{mg} / \mathrm{dl}(>50 \mu \mathrm{mol} / \mathrm{l})$.

Characteristics of the patients in the Paris and Barcelona groups were similar (Table 1). 


\section{Treatment with fibrates}

The median duration of treatment with fibrates was 1.56 years [0.56-5.12]. Thirteen patients $(65 \%)$ discontinued fibrates, after a median time of 1.38 years [0.56-3.53]. Among these patients, we distinguished those, eight in total, who discontinued fibrates for reasons that were unrelated to the worsening of liver tests: cramps without elevated serum levels of CPK $(n=1)$, decision of cardiologists $(n=2)$, non-compliance $(n=1)$, IBD flare $(n=1)$, gastric ulcer $(n=1)$, biliary stones $(n=2)$. The other five patients discontinued fibrates in a context of worsening of liver disease: two had acute cholangitis and three underwent an aggravation of cholestasis, including two who developed jaundice. In the three latter patients, increased cholestasis was likely related to the progression of PSC but by principle of precaution, clinicians in charge made the decision to discontinue fibrates in these patients. Follow-up was maintained after fibrates discontinuation for a median duration of 4.1 years [0.8-5.3].

\section{Course of laboratory tests}

Patients treated with fibrates displayed a significant decrease in ALP and ALT levels over time, $p=0.012$ and $p=0.005$ respectively (Table $2 a$ ). Such biological improvement was observed as early as three months after the introduction of fibrates (M3) and persisted until the end of the treatment (Table $2 \mathrm{~b}$ and figure $1 \mathrm{~A}$ ). At M3, ALP level was reduced by $41 \%$ compared to baseline (figure 1 A). At M3, eight patients (40\%) had ALP $<1.5$ ULN including two patients $(10 \%)$ with ALP $<1$ ULN. In contrast, no significant changes were observed in the values of GGT, AST, bilirubin, albumin, prothrombin time, platelets, IgG, IgM, creatinin or lipids, over the total duration of fibrates therapy (Table 2a). There was no significant difference between patients treated with fenofibrate and those treated with bezafibrate. 
The characteristics of responder patients defined by ALP $<1.5$ ULN at six months, were not significantly different from those of non responders, notably the proportion of advanced fibrosis or cirrhosis (Table 3). Virtually all patients who discontinued fibrates, showed a clear rebound of ALP levels soon after drug discontinuation, $\mathrm{p}=0.009$ (figure 1B). This was also the case for the patients who discontinued fibrates in a context of worsening of liver tests, with the exception of one patient. In this patient, ALP levels were still slightly decreased 6 months after discontinuation (data not shown).

\section{Course of pruritus}

Before starting fibrates, eight patients (40\%) complained of pruritus: pruritus was mild in one patient, moderate in four patients and severe in three patients (figure 2). During treatment with fibrates, the intensity of pruritus significantly decreased, $p=0.021$ (figure 2). Among the eight patients: seven patients $(88 \%)$ described improvement of pruritus (including three with complete remission); pruritus was unchanged in one patient and no patient reported worsening of pruritus. Interestingly, in one patient among the three patients with complete remission of pruritus under fibrates, discontinuation of fibrates was followed by a recurrence of itching.

\section{Course of liver stiffness}

During the treatment with fibrates, liver stiffness assessed by transient elastography, significantly increased over time, $\mathrm{p}=0.0001$ (table $2 \mathrm{a}$, figure $3 \mathrm{~A}$ ). Baseline median liver stiffness tended to be higher in patients who displayed an increase in liver stiffness $>1.5$ $\mathrm{kPa} /$ year than in patients who displayed an increase in liver stiffness $\leq 1.5 \mathrm{kPa} /$ year, i.e. $12 \mathrm{kPa}$ [8.8-35] and $9.5 \mathrm{kPa}$ [6.6-15.1], respectively, $\mathrm{p}=0.065$ (figure $3 \mathrm{~B}$ ). 


\section{Clinical events}

During treatment with fibrates, one gallbladder carcinoma occurred. After the discontinuation of fibrates, the following clinical events occurred: one cholangiocarcinoma of the common bile duct and four liver transplantations (LT). These events are reported in detail in Table 4.

Four-year transplant-free survival was $80 \%$. The observed survival was not significantly different from that predicted by Mayo Risk Score, $\mathrm{p}=0.31$.

\section{Discussion}

Our study shows that in a small group of PSC patients who keep ALP above 1.5 ULN after an extensive period under UDCA monotherapy, prolonged therapy with fibrates is effective in eliciting a biochemical response. Indeed, 3 months after fibrates were introduced, ALP were decreased by $41 \%$ and were normalized in $10 \%$ of the patients. Pruritus also significantly improved under treatment. Noticeably, there was a clear rebound of cholestasis and pruritus after fibrates were discontinued. The rebound in ALP levels was also observed in the patients who stopped fibrates because of worsening of blood liver tests. These findings support the lack of relationship between the intake of fibrates administration and the worsening of cholestasis. These results are in keeping with those of short-term non-blinded studies from Japan $[14,16,17]$. The present study of fibrates in the treatment of PSC, the largest one in the Western world, indicates that fibrates may indeed represent a viable medical option.

In contrast with $\mathrm{PBC}$, there is no validated definition of an inadequate biochemical response to UDCA during PSC, making debatable our choice of ALP above 1.5 ULN as inclusion criteria. However, several long-term studies indicated that normal or near-normal 
ALP levels, either spontaneously or under treatment, were associated with a better outcome [20-22]. Therefore, ALP above 1.5 ULN under UDCA is likely a reasonable criterion to identify patients requiring new treatments. The dramatic improvement in ALP compares favorably with other potential drugs. Indeed, a $26 \%$ reduction of serum ALP levels was observed in the recent phase II norUDCA trial (with the highest dose) [23]. Moreover, patients in the norUDCA trial were UDCA free [23] whereas those in our study were "UDCA resistant" and more likely "difficult to treat" patients. Another impressive result was the itchrelieving effect, in keeping with those observed in the fibrate-PBC studies $[11,12]$. The mechanisms by which fibrates may exert this effect are unknown. It remains to determine whether these mechanisms rely on specific properties or on the general anticholestatic effects.

This study was not designed nor powered to properly assess safety. Nevetheless, no event indicating major safety concerns was noted in this small uncontrolled study. Main adverse events of fibrates are usually muscular pains and impaired renal function. Here, only one patient discontinued fibrate because of cramps. No significant increase in creatinine level was observed. Three patients showed an increase of cholestasis under fibrates, which was likely related to the progression of PSC. However, a controlled study is needed in order to make any clear conclusion as to whether the worsening cholestasis could be related to fibrates or not. One major clinical event (gallbladder carcinoma) occurred during fibrate therapy and seem unrelated to fibrates, since this biliary cancer is a well-known complication of PSC, whose occurrence is distinct from the general course of PSC. Occurrence of intra-hepatic biliary stones in two patients deserves special comments. A lithogenic effect of fibrates was previously reported, so that, despite a lack of clinical symptoms, a discontinuation of fibrates was decided. However, spontaneous occurrence of biliary lithiasis has also been reported in up to $26-56 \%$ of PSC patients $[24,25]$, so that the causal role of fibrates in our cases was 
uncertain. Moreover, an association between fibrate therapy and cholelithiasis is clearly established only for clofibrate [26]. Nevertheless, special attention should be paid to biliary stones in future studies.

This bi-centric study has some limitations. It is a small, retrospective, uncontrolled study with its intrinsic bias, missing data and cases of fibrates discontinuation for non-liver related reasons. However, it combines both the largest Western study population and the longest duration of treatment, up to 5 years. Despite a beneficial effect on biochemistry and pruritus, there was no direct evidence that the general course of the disease (transplant-free survival) was improved. We know from UDCA trials that improvements in ALP can be dissociated from clinical endpoints [6]. Median duration of fibrate therapy was probably too short (1.56 years) for hard clinical end-points and more importantly, numerous patients had advanced disease when treatment was started, including cirrhosis in one third. Likewise, liver stiffness increased in patients with serial measurements but levels with established prognostic value ( $>$ $1.5 \mathrm{kPa} /$ year) [19] were mostly noted in patients with high baseline values. Not surprinsingly, the effects of fibrates appear to be better in PBC patients with early stages of liver disease [12] and the absence of cirrhosis has been proposed as a predictive factor of response to fibrates in the PSC Japanese experience [17]. Probably due to the small size of our study population, we did not identify any predictor of ALP improvement in response to fibrates. Notably, the absence of advanced fibrosis or cirrhosis was not found to be predictive of response.

This underlines the need of a careful design of future PSC therapeutic trials including risk stratification at entry and choice of appropriate surrogate markers measuring clinically meaningful outcomes. Fully validated surrogate endpoints are presently lacking but according 
to a recent consensus process initiated by the International PSC Study Group, histology, ALP and transient elastography are the most likely candidates (possibly combined in a co-primary endpoint) [27, 28].

\section{Conclusions}

In summary, we found that, in PSC patients with incomplete response to UDCA, the addition of fibrates was successful in decreasing serum alkaline phosphatase and in improving pruritus. These observations provide a rationale for larger and prospectively designed studies to establish efficacy and safety of fibrates in PSC. 


\section{References}

[1] Hirschfield GM, Karlsen TH, Lindor KD, Adams DH. Primary sclerosing cholangitis. Lancet. 2013;382(9904):1587-99.

[2] Lazaridis KN, LaRusso NF. Primary Sclerosing Cholangitis. N Engl J Med. 2016;375(25):2501-2.

[3] European Association for the Study of the L. EASL Clinical Practice Guidelines: management of cholestatic liver diseases. J Hepatol. 2009;51(2):237-67.

[4] Chapman R, Fevery J, Kalloo A, Nagorney DM, Boberg KM, Shneider B, et al. Diagnosis and management of primary sclerosing cholangitis. Hepatology. 2010;51(2):660-78.

[5] Lindor KD, Kowdley KV, Harrison ME, American College of G. ACG Clinical Guideline: Primary Sclerosing Cholangitis. Am J Gastroenterol. 2015;110(5):646-59.

[6] Lindor KD, Kowdley KV, Luketic VA, Harrison ME, McCashland T, Befeler AS, et al. High-dose ursodeoxycholic acid for the treatment of primary sclerosing cholangitis. Hepatology. 2009;50(3):808-14.

[7] Nakai S, Masaki T, Kurokohchi K, Deguchi A, Nishioka M. Combination therapy of bezafibrate and ursodeoxycholic acid in primary biliary cirrhosis: a preliminary study. Am J Gastroenterol. 2000;95(1):326-7.

[8] Ohira H, Sato Y, Ueno T, Sata M. Fenofibrate treatment in patients with primary biliary cirrhosis. Am J Gastroenterol. 2002;97(8):2147-9.

[9] Levy C, Peter JA, Nelson DR, Keach J, Petz J, Cabrera R, et al. Pilot study: fenofibrate for patients with primary biliary cirrhosis and an incomplete response to ursodeoxycholic acid. Aliment Pharmacol Ther. 2011;33(2):235-42.

[10] Lens S, Leoz M, Nazal L, Bruguera M, Pares A. Bezafibrate normalizes alkaline phosphatase in primary biliary cirrhosis patients with incomplete response to ursodeoxycholic acid. Liver Int. 2014;34(2):197-203.

[11] Corpechot C, Chazouilleres 0, Rousseau A, Le Gruyer A, Habersetzer F, Mathurin $\mathrm{P}$, et al. A placebo-controlled trial of bezafibrate in primary biliary cholangitis. $\mathrm{N}$ Engl J Med. 2018; 378(23): 2171-2181.

[12] Reig A, Sese P, Pares A. Effects of Bezafibrate on Outcome and Pruritus in Primary Biliary Cholangitis With Suboptimal Ursodeoxycholic Acid Response. Am J Gastroenterol. 2018; 113(1):49-55.

[13] Ghonem NS, Assis DN, Boyer JL. Fibrates and cholestasis. Hepatology. 2015;62(2):635-43.

[14] Mizuno S, Hirano K, Tada M, Yamamoto K, Yashima Y, Yagioka H, et al. Bezafibrate for the treatment of primary sclerosing cholangitis. J Gastroenterol. 2010;45(7):758-62.

[15] Dejman A, Clark V, Martin P, Levy C. Fenofibrate Improves Alkaline Phosphatase in Primary Sclerosing Cholangitis. Gastroenterology. 2013;144(5, Supplement 1):S1028S9.

[16] Mizuno S, Hirano K, Isayama H, Watanabe T, Yamamoto N, Nakai Y, et al. Prospective study of bezafibrate for the treatment of primary sclerosing cholangitis. J Hepatobiliary Pancreat Sci. 2015;22(10):766-70.

[17] Mizuno S, Isayama H, Hirano K, Watanabe T, Takahara N, Kogure H, et al. Factors predictive of the efficacy of bezafibrate therapy in patients with primary sclerosing cholangitis. Hepatol Res. 2017; 47(11):1102-07.

[18] Kim WR, Therneau TM, Wiesner RH, Poterucha JJ, Benson JT, Malinchoc M, et al. A revised natural history model for primary sclerosing cholangitis. Mayo Clin Proc. 2000;75(7):688-94. 
[19] Corpechot C, Gaouar F, El Naggar A, Kemgang A, Wendum D, Poupon R, et al. Baseline values and changes in liver stiffness measured by transient elastography are associated with severity of fibrosis and outcomes of patients with primary sclerosing cholangitis. Gastroenterology. 2014;146(4):970-9.

[20] Lindstrom L, Hultcrantz R, Boberg KM, Friis-Liby I, Bergquist A. Association between reduced levels of alkaline phosphatase and survival times of patients with primary sclerosing cholangitis. Clin Gastroenterol Hepatol. 2013;11(7):841-6.

[21] Rupp C, Rossler A, Halibasic E, Sauer P, Weiss KH, Friedrich K, et al. Reduction in alkaline phosphatase is associated with longer survival in primary sclerosing cholangitis, independent of dominant stenosis. Aliment Pharmacol Ther. 2014;40(1112):1292-301.

[22] de Vries EM, Wang J, Leeflang MM, Boonstra K, Weersma RK, Beuers UH, et al. Alkaline phosphatase at diagnosis of primary sclerosing cholangitis and 1 year later: evaluation of prognostic value. Liver Int. 2016;36(12):1867-75.

[23] Fickert P, Hirschfield GM, Denk G, Marschall HU, Altorjay I, Farkkila M, et al. norUrsodeoxycholic acid improves cholestasis in primary sclerosing cholangitis. J Hepatol. 2017;67(3):549-58.

[24] Awadallah NS, Chen YK, Piraka C, Antillon MR, Shah RJ. Is there a role for cholangioscopy in patients with primary sclerosing cholangitis? Am J Gastroenterol. 2006;101(2):284-91.

[25] Ruiz A, Lemoinne S, Carrat F, Corpechot C, Chazouilleres O, Arrive L. Radiologic course of primary sclerosing cholangitis: assessment by three-dimensional magnetic resonance cholangiography and predictive features of progression. Hepatology. 2014;59(1):242-50.

[26] Davidson MH, Armani A, McKenney JM, Jacobson TA. Safety considerations with fibrate therapy. Am J Cardiol. 2007;99(6A):3C-18C.

[27] Ponsioen CY, Chapman RW, Chazouilleres O, Hirschfield GM, Karlsen TH, Lohse AW, et al. Surrogate endpoints for clinical trials in primary sclerosing cholangitis:

Review and results from an International PSC Study Group consensus process. Hepatology. 2016;63(4):1357-67.

[28] Ponsioen CY, Lindor KD, Mehta R, Dimick-Santos L. Design and endpoints for clinical trials in primary sclerosing cholangitis. Hepatology. 2018. 


\section{Tables}

Table 1: Characteristics of patients at inclusion

\begin{tabular}{|c|c|c|c|c|}
\hline Baseline Characteristics & $\begin{array}{c}\text { Paris } \\
+ \\
\text { Barcelone }\end{array}$ & Paris & Barcelone & $\begin{array}{c}\text { Paris vs Barcelona } \\
\text { p }\end{array}$ \\
\hline $\mathrm{n}$ & 20 & 14 & 6 & \\
\hline Male sex (\%) & $15(75 \%)$ & $10(71 \%)$ & $5(83 \%)$ & 0.57 \\
\hline IBD (\%) & $14(70 \%)$ & $9(64 \%)$ & $5(83 \%)$ & 0.39 \\
\hline Age (years) & $43.8[21-73]$ & 47 [21-73] & $40[33-58]$ & 0.84 \\
\hline $\begin{array}{l}\text { Time between diagnosis of } \\
\text { PSC and inclusion } \\
\text { (years) }\end{array}$ & $6.7[1.9-20.4]$ & $6.5[1.9-20.2]$ & 8.4 [2.9-20.4] & 0.54 \\
\hline Bilirubin (mg/dl) & $0.9[0.4-3.3]$ & $1.0[0.4-2.6]$ & $0.8[0.7-3.3]$ & 0.43 \\
\hline ALP (xULN) & $3.2[1.7-8.4]$ & $3.2[1.7-8.4]$ & $3.3[1.9-5.7]$ & 0.97 \\
\hline AST (x ULN) & $1.8[0.9-5.4]$ & $2.0[1-5.4]$ & $1.6[0.9-2.9]$ & 0.65 \\
\hline Albumin $(\mathrm{g} / \mathrm{dl})$ & $4.1[3-4.8]$ & $4.1[3-4.8]$ & $4.1[4-4.3]$ & 0.87 \\
\hline Mayo Risk Score & $\begin{array}{c}+0.18 \\
{[-0.95 ;+2.48]}\end{array}$ & $\begin{array}{c}+0.33 \\
{[-0.95 ;+2.48]}\end{array}$ & $\begin{array}{c}-0.22 \\
{[-0.78 ;+0.29]}\end{array}$ & 0.30 \\
\hline $\begin{array}{ll}\text { Transient } & \text { Elastography } \\
(\mathrm{kPa}) \mathrm{n}=20 & \end{array}$ & 11 [6.6-35] & $11[7.2-35]$ & 10 [6.6-15.1] & 0.22 \\
\hline $\begin{array}{l}\text { Duration of treatment with } \\
\text { fibrates (years) }\end{array}$ & $1.56[0.56-5.12]$ & $1.46[0.56-5.12]$ & $3.38[1.37-4.42]$ & 0.27 \\
\hline
\end{tabular}


Table 2: Course of parameters during treatment with fibrates

2a. Changes in biochemical and stiffness values over the total duration of treatment with fibrates

\begin{tabular}{|l|c|c|c|}
\hline \multirow{2}{*}{ Parameters } & \multicolumn{3}{|c|}{ Overall change } \\
\cline { 2 - 4 } & slope & $\begin{array}{c}\text { Standard } \\
\text { deviation }\end{array}$ & $\begin{array}{c}\text { p } \\
\text { (linear mixed model) }\end{array}$ \\
\hline AST & -0.006 & 0.006 & 0.338 \\
\hline ALT & -0.026 & 0.009 & $\mathbf{0 . 0 0 5}$ \\
\hline GGT & -0.023 & 0.020 & 0.252 \\
\hline ALP & -0.022 & 0.009 & $\mathbf{0 . 0 1 2}$ \\
\hline Total Bilirubin & -0.013 & 0.113 & 0.908 \\
\hline Albumin & 0.026 & 0.018 & 0.163 \\
\hline Prothrombin time & -0.038 & 0.066 & 0.572 \\
\hline Platelets & -0.205 & 0.820 & 0.803 \\
\hline IgM & -0.005 & 0.003 & 0.168 \\
\hline IgG & -0.029 & 0.017 & 0.091 \\
\hline Creatinin & -0.088 & 0.070 & 0.206 \\
\hline Total Cholesterol & -0.010 & 0.006 & 0.091 \\
\hline Triglycerides & -0.002 & 0.002 & 0.373 \\
\hline CPK & -0.582 & 1.100 & 0.600 \\
\hline Liver stiffness & 3.802 & 0.878 & $\mathbf{0 . 0 0 0 1}$ \\
\hline & & & \\
\hline
\end{tabular}

Data were obtained by linear mixed model. 
2b. Changes in biochemical values after 3 months of treatment with fibrates

\begin{tabular}{|c|c|c|}
\hline \multirow[t]{2}{*}{ Parameters } & \multicolumn{2}{|c|}{ Change at M3 } \\
\hline & $\begin{array}{l}\text { Percentage change } \\
\text { M3 versus baseline }\end{array}$ & $\begin{array}{c}\mathbf{p} \\
\text { (Wilcoxon) }\end{array}$ \\
\hline AST & $-18 \%[-54+47]$ & 0.055 \\
\hline ALT & $-38 \%[-72+56]$ & 0.010 \\
\hline GGT & $-26 \%[-78+57]$ & 0.001 \\
\hline ALP & $-41 \%[-77+10]$ & 0.0002 \\
\hline Total Bilirubin & $-15 \%[-77+71]$ & 0.235 \\
\hline $\operatorname{IgM}$ & $-11 \%[-24+22]$ & 0.713 \\
\hline $\operatorname{IgG}$ & $-3 \%[-25+11]$ & 0.438 \\
\hline Creatinin & $+5 \%[-16+36]$ & 0.209 \\
\hline Total Cholesterol & $-4 \%[-34+30]$ & 0.413 \\
\hline Triglycerides & $-11 \%[-54+191]$ & 0.520 \\
\hline $\mathrm{CPK}$ & $-42 \%[-83+81]$ & 0.313 \\
\hline
\end{tabular}

Percentage changes are expressed as median with ranges. 
Table 3: Comparison of responders and non responders to fibrates

\begin{tabular}{|c|c|c|c|}
\hline & $\begin{array}{c}\text { Responders } \\
\text { ALP }<1.5 \text { ULN at M6 }\end{array}$ & $\begin{array}{c}\text { Non-responders } \\
\text { ALP }>1.5 \text { ULN at M6 } \\
\end{array}$ & $\mathbf{p}$ \\
\hline $\mathrm{n}$ & 7 & 10 & \\
\hline Age (years) & 35 [26-53] & 48 [21-73] & 0.19 \\
\hline Sex Male $(\%)$ & $6(85 \%)$ & $7(70 \%)$ & 0.45 \\
\hline IBD (\%) & $5(72 \%)$ & $8(80 \%)$ & 0.68 \\
\hline Liver stiffness $(\mathrm{kPa})$ & $11.8[6.6-17.5]$ & $9[8 .-17.5]$ & 0.63 \\
\hline Severe fibrosis (\%) & $5(71 \%)$ & $4(40 \%)$ & 0.28 \\
\hline Cirrhosis (\%) & $3(43 \%)$ & $2(20 \%)$ & 0.37 \\
\hline ALP (ULN) & $2.5[2-6]$ & $3.9[1.7-8.4]$ & 0.81 \\
\hline AST (ULN) & $1.2[0.9-4.4]$ & $2.3[0.9-3.7]$ & 0.33 \\
\hline Albumin $(\mathrm{g} / \mathrm{l})$ & $41[40-48.1]$ & $37.7[30.2-43]$ & 0.11 \\
\hline Bilirubin $(\mu \mathrm{mol} / \mathrm{l})$ & $14[7-24.3]$ & $16.5[12-56]$ & 0.15 \\
\hline Platelets (G/1) & 255 [190-383] & 315 [104-467] & 0.36 \\
\hline $\begin{array}{l}\text { Time between } \\
\text { diagnosis of PSC and } \\
\text { fibrates (years) }\end{array}$ & $7.4[4.3-20.4]$ & $5.4[1.9-20.2]$ & 0.42 \\
\hline
\end{tabular}


Table 4 : Main clinical events

\begin{tabular}{|c|c|c|c|c|c|c|}
\hline Patient & $\begin{array}{l}\text { Event } \\
\text { (cause) }\end{array}$ & $\begin{array}{c}\text { Time } \\
\text { between } \\
\text { diagnosis } \\
\text { of PSC } \\
\text { and event } \\
\text { (years) }\end{array}$ & $\begin{array}{c}\text { Fibrosis } \\
\text { stage at } \\
\text { initiation } \\
\text { of } \\
\text { fibrates* }\end{array}$ & $\begin{array}{c}\text { Time } \\
\text { between } \\
\text { start of } \\
\text { fibrates } \\
\text { and event } \\
\text { (years) }\end{array}$ & $\begin{array}{c}\text { Under Fibrates } \\
\text { or } \\
\text { After } \\
\text { discontinuation } \\
\text { (cause of } \\
\text { discontinuation) }\end{array}$ & $\begin{array}{c}\text { Time } \\
\text { between } \\
\text { discontinuation } \\
\text { of fibrates and } \\
\text { event } \\
\text { (years) }\end{array}$ \\
\hline 1 & $\begin{array}{l}\text { Gallbladder } \\
\text { carcinoma }\end{array}$ & 11 & $\mathrm{~F} 4$ & 2.2 & Under fibrates & \\
\hline 3 & $\begin{array}{l}\text { Hilar } \\
\text { cholangio- } \\
\text { carcinoma }\end{array}$ & 10.3 & $\mathrm{~F} 4$ & 1.29 & After (jaundice) & 0.1 \\
\hline 4 & $\begin{array}{l}\text { LT } \\
\text { (recurring } \\
\text { cholangitis) }\end{array}$ & 8.9 & F3 & 2.7 & After (cholestasis) & 1.1 \\
\hline 5 & $\begin{array}{l}\text { LT } \\
\text { (decompensated } \\
\text { cirrhosis ) }\end{array}$ & 6.4 & F3 & 2.2 & $\begin{array}{l}\text { After } \\
\text { (non-compliance) }\end{array}$ & 0.7 \\
\hline 6 & $\begin{array}{l}\text { LT } \\
\text { (decompensated } \\
\text { cirrhosis ) }\end{array}$ & 7.9 & $\mathrm{~F} 4$ & 1.8 & After (cramps) & 1.2 \\
\hline 7 & $\begin{array}{l}\mathrm{LT} \\
\text { (recurring } \\
\text { cholangitis) }\end{array}$ & 6.2 & F3 & 3.3 & After (cholangitis) & 1.9 \\
\hline
\end{tabular}

* Fibrosis stage was stated according to the most severe result of histology or liver stiffness performed before inclusion.

$\mathrm{LT}$, liver transplantation 


\section{Figure Legends}

Figure 1: Course of alkaline phosphatase during treatment with Fibrates and after discontinuation

A. PSC patients who showed an incomplete biochemical response (Alkaline Phosphatase $($ ALP) $>1.5 x$ upper limit of normal) to UDCA were treated with fibrates in addition to UDCA. Change in alkaline phosphatase was analyzed. Bars represent means with SEM (standard error of the mean). $\mathrm{n}=$ number of patients. Red line stands for 1.5 upper limit of normal (ULN).

B. This figure represents the thirteen patients who discontinued fibrates for any reason. Each line stands for one patient.

$* \mathrm{p}<0.05$

\section{Figure 2: Course of pruritus during treatment with Fibrates}

This figure represents the eight patients who had pruritus when fibrates treatment was started. Pruritus was recorded according to a scale of $0-3: 0=$ absent, $1=$ mild, $2=$ moderate and $3=$ severe.

$* \mathrm{p}<0.05$

\section{Figure 3: Course of liver stiffness during treatment with Fibrates}

A. Spaghetti plot of liver stiffness measurements (LSM). $n=$ number of patients.

B. Baseline liver stiffness in patients who showed an increase $>1.5 \mathrm{kPa}$ per year versus patients who showed an increase $\leq 1.5 \mathrm{kPa}$ per year. Bars represent means with SEM (standard error of the mean). 